\title{
i Retos y oportunidades de la integración centroamericana
}

\author{
Miguel A. Lazo \\ Universidad para la Cooperación \\ Internacional, Costa Rica
}

Cuando se habla sobre el proceso de integración centroamericana, siempre se plantean dudas sobre el status real de ésta, ya que la misma ha sido utilizada una y otra vez por los Gobiernos de los distintos países en su afán de querer demostrar resultados satisfactorios o que se han realizado esfuerzos significativos por tratar de conseguirlo. Es por dicha razón que, desde hace muchas décadas, los esfuerzos por unir a la región han sido muchísimos, en diversos momentos y en diferentes grados de intensidad atendiendo a las necesidades que se tengan. Está claro que hasta la fecha ninguno se ha podido concretizar por completo. Por otra parte, el no haber logrado esa integración anhelada ha traído consigo muchos planteamientos sobre los beneficios que se podrían tener si se consigue. Uno de los últimos estudios sobre este tema es el realizado por el Dr. Caldentey, quien expresó entre sus resultados la necesidad de analizar la integración más allá del punto de vista comercial, haciendo énfasis en la presencia de un nuevo regionalismo estratégico donde se deben reforzar los compromisos en materia de unión aduanera e integración económica (Caldentey, 2014). Por tal razón, el objetivo de este artículo es analizar brevemente estos esfuerzos, así como brindar un panorama actual de la situación económica de la región y de las oportunidades existentes.

\section{El proceso de integración centroamericana}

Los esfuerzos por unir a la región centroamericana datan de varias décadas, incluso siglos atrás, ya que se registran muchos intentos a lo largo del tiempo; uno de los primeros fue después de la Independencia de España en 1821, cuando se dieron presiones e intentos fallidos de parte de México por formar un imperio entre 1822 y 1823, el cual sirvió de impulso para que las cinco 
naciones en ese entonces pasaran a formar la Federación de Estados Centroamericanos entre 1824 y 1838. Lastimosamente, el sueño no pudo seguir, quedando sólo los deseos de conformar una vez más, $\mathrm{y}$ en mejores términos, una sola región. Los esfuerzos continuaron y permitieron que a mediados del siglo pasado se suscribiera el Tratado General de Integración Económica Centroamericana (TGIE), el 13 de diciembre de 1960, que se convirtió en el instrumento jurídico que estableció el Mercado Común Centroamericano (MCCA), que quedó integrado por Costa Rica, El Salvador, Guatemala, Honduras y Nicaragua, mediante el establecimiento de una zona de libre comercio y la adopción de un arancel centroamericano uniforme; a éste se ha incorporado Panamá en años recientes.

Estos primeros intentos pueden compararse con los actuales, con la diferencia que ahora el proceso sigue latente y se alimenta de la necesidad que existe como región de acceder a un mundo globalizado. En años recientes, Centroamérica ha sufrido todos los impactos de la crisis que se han gestado a nivel mundial, desde la crisis que estalló en el 2008 a causa de la "Burbuja Inmobiliaria" hasta la más reciente disputa "comercial" entre las potencias mundiales más fuertes que son Estados Unidos - que es uno de sus principales socios- con China, quien poco a poco se ha ido posi- cionando en la región. Lo importante destacar de todo esto, aunque sea en términos negativos, es lo frágil que es nuestra región y economía ante los diversos fenómenos mundiales, lo que nos incita a pensar en nuevas maneras para tratar de mejorar este panorama.

Por lo indicado en el apartado anterior, creo que es necesario mencionar el "movimiento" llevado a cabo por muchos países y no sólo por la región a finales del siglo pasado, momento en el cual -y quizá presionado por diversas entidades- la mayoría de los países se embarcaron en un proceso de apertura comercial que tenía como finalidad insertar las economías en el comercio mundial. Esto con la premisa de los beneficios que se obtendrían del proceso mediante la intensificación del comercio, la atracción de la Inversión Extranjera Directa (IED) y el fortalecimiento del papel de las remesas en sus economías. Bueno, eso es lo que se pretendía, sin embargo, en el trayecto y con los distintos embates, se han constatado las limitaciones de los países de la región que tienen escasa o nula capacidad para incidir de alguna manera en las condiciones de la oferta y demanda globales (Programa Estado de la Nación, 2010).

\section{Impactos económicos sustanciales}

Por otra parte, si analizamos brevemente los efectos en términos económicos de los últimos sucesos 
en la economía mundial, se estima que la economía aún no se ha recuperado de los efectos adversos ocasionados por la crisis económica que impactó en 2008, ya que aún se presenta una coyuntura de bajo dinamismo y fuerte incertidumbre en muchos ámbitos. Si a este panorama desalentador se le agregan otros factores como la reducción en la demanda global, la caída de los precios de las materias primas, la desaceleración de la economía china, la crisis de la zona euro y el escaso dinamismo regional en su actividad económica, definitivamente surgen más inquietudes.

Con respecto a la región centroamericana en sí, tenemos la famosa "década perdida" que se vivió en los 80 , después tenemos un período de bonanza que hizo olvidar esa etapa en la década de los 90 e inicios del 2000 -período de apertura comercial-, para llegar a la etapa de contracciones ocasionadas por los fenómenos mundiales que nos brindan los siguientes aspectos importantes:

1) La relevancia y el papel que juega Estados Unidos, ya que la desaceleración de esta economía trajo consigo una reducción en la actividad económica que se vio reflejada en la disminución de las exportaciones y en la reducción de las remesas que son consideradas un pilar clave dentro de la matriz económica.
2) El aumento en la presión de las finanzas públicas y en los ingresos estatales.

3) El tratado de los Estados Unidos con la región, así como los flujos de capital, de IED y de turismo que se vieron afectados por la propia recesión (Aráuz, 2009). En este punto es de mencionar que la región centroamericana rápidamente buscó medidas para tratar de reducir los efectos colaterales, lo cual implicó que en un inicio, los países miembros de la región desarrollarán planes nacionales o programas internos para resolver el problema, ahí podemos mencionar el "Programa Global Anticrisis" de El Salvador, el "Plan Escudo" de Costa Rica, el "Programa Nacional de Emergencia y Recuperación Económica" de Guatemala, el "Plan Nacional para la Conservación y Generación de Empleo 2009" de Nicaragua y el "Programa de Defensa de la Producción, el Crecimiento y el Empleo" de Honduras. De igual forma, los países se manifestaron dispuestos a continuar con los esfuerzos para lograr la integración regional y enfrentar la crisis en conjunto -de alguna manera, ese panorama brindó nuevamente un punto de partida-; claramente, estos objetivos aún se persiguen a la fecha por la falta de coordinación entre las distintas voluntades políticas (Egenhoff y Stein, 2010) que sigue vigente. En años recientes, la economía ha seguido la tendencia 
y ha presentado retos a nivel regional por la crisis de la zona euro, la desaceleración de la economía china o por la presentación de fenómenos políticos como el referéndum con el que se aprobó la salida del Reino Unido de la Unión Europea (Brexit) (CEPAL, 2017a) o por el cambio de Gobierno en Estados Unidos con la victoria de los republicanos y la subida al poder de su candidato y ahora presidente Donald Trump.

\section{Recuperación gradual de la economía}

Los impactos económicos y los fenómenos políticos presentados a nivel mundial han traído una serie de retos importantes, más aún si consideramos que en el 2016 el crecimiento mundial fue el más débil desde 2008-2009. Sin embargo, la economía mundial ha mostrado signos de mejoría en su recuperación, a tal punto que en general se prevé un crecimiento mundial en este último año gracias a la lenta recuperación de las principales economías (Estados Unidos, China, Unión Europa y Japón), aunque con la presencia de una amplia dispersión de riesgos por las vulnerabilidades existentes (Fondo Monetario Internacional, 2017a). En este contexto de incertidumbre mundial, la región centroamericana mostró señales positivas en términos de crecimiento económico para el 2018 (3.9\%), ya que presentó una previsión mayor incluso que la de América Latina y
El Caribe (1.9\%), esto según datos del Fondo Monetario Internacional (2017b). Por ende, el reto es dar sostenibilidad a este crecimiento económico para la región y retomar el tema de la integración y de los beneficios que se podrían obtener si se visualiza esta integración como una herramienta para el logro de las metas trazadas y no nada más como un fin; me atrevería a decir que lo ideal sería tomar a esta integración como un punto crítico de agenda y luchar por su concretización.

\section{Negociaciones comerciales con otras regiones y países}

La globalización ha estado con nosotros desde hace muchos años, esto ha hecho que se haya profundizado y diversificado, así se ha tenido claro que, para lograr resultados satisfactorios, la economía de un país debe estar abierta al comercio y a la inversión con el resto del mundo. La región centroamericana no es la excepción, ya que ha sido parte de este proceso a través de todos sus países. En ese sentido, la figura de los Acuerdos Comerciales Regionales (ACR) es un término que adopta especial importancia, así como la forma en que se preparan y negocian estos acuerdos con otros bloques comerciales. Habría que indicar que lo ideal sería abordar estos bloques más allá del aumento del flujo comercial entre las partes, ya que aunque casi todos los acuerdos comerciales poseen dispo- 
siciones relacionadas a aranceles preferenciales, los ACR contienen un amplio abanico de elementos que van más allá de los aranceles, y es ahí donde se podrían incluir la inversión, los servicios, la protección de la propiedad intelectual, la competencia, el grado de integración con el mercado, entre muchos otros aspectos (Organización Mundial del Comercio, 2011). Al analizar a grandes rasgos la evolución del comercio de la región, se puede constatar el aumento de las exportaciones intrarregionales que pasaron de US\$1,426 millones en 1994 a US\$ 8,469 millones en 2016, lo que implica un crecimiento promedio anual del $8.4 \%$, tasa que fue mayor a la obtenida de las exportaciones extrarregionales del $7.6 \%$ en el mismo período, aunque con valores menores si comparamos el monto de éstas (Cordero, 2017). Sin embargo, lo que resulta conveniente al revisar estas cifras son los bienes inmersos dentro del flujo comercial, así como el aumento en el valor de las exportaciones hacia terceros socios comerciales. En este punto, vale mencionar los esfuerzos de la región para afrontar los retos en materia comercial, entre ellos se puede encontrar la reciente "Estrategia Centroamericana de Facilitación del Comercio y Competitividad con énfasis en Gestión Coordinada de Fronteras" que surgió con la finalidad de mejorar los procedimientos de control e infraestructura inadecuados existentes.

\section{La importancia del sector servicios}

La región de América Latina ha presentado muchas restricciones en su crecimiento (factores internos y externos), sin embargo, la principal de todas ellas ha sido la baja productividad, que la ha llevado a ser catalogada como una de las determinantes más importantes en la desaceleración de la región desde la década de los 80 (Ros, 2011). En los últimos años, la tendencia ha cambiado y algunos sectores reflejan un importante crecimiento, destacando uno de ellos en especial: el sector servicios, que en las últimas décadas se ha convertido en el segmento más dinámico del comercio mundial con un crecimiento más rápido que el tradicional comercio de mercancías, lo que sugiere que los servicios son más resistentes a las perturbaciones económicas mundiales (Organización Mundial del Comercio, 2015). Por tradición y considerando los recursos naturales con que la región cuenta, la mayor parte de los países latinoamericanos ha basado su matriz productiva en el sector agropecuario, situación que no es exenta de la región centroamericana, lo que le ha permitido cometer el error de no modificar su estructura productiva. Sin embargo, los esfuerzos por cambiar esta situación se están realizando; es aquí donde surge una importante oportunidad para la región centroamericana dentro del creciente sector de servicios. Esta situación obedece a que las 
actividades que en algún momento eran operadas por multinacionales de los países desarrollados se han tercerizado y ubicado en países emergentes para reducir costos, así como por la revolución en las tecnologías de información y en la liberalización del comercio - demanda cubierta en un inicio por países como la India, los asiáticos, entre otros-, donde el beneficio principal de esta participación radica en el desarrollo sostenible en que se ven inmersos otros sectores como el industrial y agropecuario, los que se hallan relacionados indirectamente en actividades como la de transporte, comunicaciones, tecnología y logística.

\section{Atracción de la IED}

Otro de los principales beneficios de participar de manera activa en el comercio mundial proviene de la atracción de la IED; la región centroamericana constituye una importante plataforma debido a su más de medio millón de kilómetros cuadrados y 46 millones de habitantes, aparte de que goza de ventajas naturales que su posición geográfica le brinda al servir de enlace entre las Américas y de conexión entre las principales rutas marítimas del comercio, además de los esfuerzos por mejorar su infraestructura, el apoyo brindado al sector turismo y sus avances en el proceso de integración económica, entre muchos otros aspectos que la logran situar en una mejor posición a los ojos del mundo. El flujo de IED a nivel mundial y de la región de América Latina en la última década venía en aumento, sin embargo, los fenómenos de los que hemos hablado han permitido una desaceleración en sus entradas hasta llegar a un $7.9 \%$ en 2016 , lo que ha dificultado en cierta medida el arribo de inversionistas (Comisión Económica para América Latina y el Caribe, 2017b). Por ende, ha surgido el reto de mejorar los niveles de inversión y cambiar esta perspectiva mediante la participación activa del Estado y de los diversos sectores. Una reciente prueba de los esfuerzos que se han venido realizando es la firma del acuerdo comercial de la región con Corea del Sur, el cual abre un nuevo mercado comercial, de servicios y de inversores para la región que puede traer importantes beneficios; también el reciente interés de China por fomentar relaciones diplomáticas y comerciales con la región centroamericana, un tema que sin duda valdría la pena analizar.

\section{Conclusiones}

Los resultados de este breve análisis permiten extraer las conclusiones que se detallan a continuación, que además pueden ser contrastadas en estudios más complejos que contemplen más escenarios, componentes y una mayor representatividad de los datos: 
1. La región centroamericana tiene una historia de inestabilidad, crisis económicas e intentos fallidos en sus deseos de integración que datan de muchas décadas. Indudablemente, esto ha pasado factura por la percepción adquirida. La incapacidad para crecer a un ritmo económico sostenido y de tener un desarrollo próspero son las principales manifestaciones del clima de inestabilidad que se vive y que se fortalece con una serie de restricciones que hacen más complicado este panorama. Sin embargo, en muchos aspectos, la región presenta signos de mejoría que deben ser potenciados considerando las fortalezas y oportunidades con las que se cuenta, que lo convierten en un reto complejo que demanda tiempo y esfuerzo de sus miembros, reto que se ha convertido en compromiso del que ya hay evidencias al observar las distintas agendas de trabajo regional adoptadas por los países.

2. Si se considera que una de las principales restricciones a nivel regional es la baja productividad que se tiene, se hace necesario desarrollar los mecanismos precisos para modificar la matriz productiva con que se cuenta y fortalecer el sector de servicios que en los últimos años ha presentado incrementos significativos a nivel mundial y regional, esto a pesar de la reciente desaceleración. Lo anterior implica que la región debe pasar de depender directamente de las exportaciones que se efectúan de productos primarios - productos que presentaron una caída en los precios en años recientes- a las exportaciones de servicios, lo que lleva asociado el fortalecimiento de las distintas industrias relacionadas a este sector y de los beneficios que se pueden obtener por esa experticia. En este punto, se hace clave la participación de los distintos sectores -especialmente del sector privado- junto con el Estado, quien es el que debe llevar la batuta para ejecutar los esfuerzos necesarios.

3. Por último, la globalización es un proceso arraigado desde hace muchas décadas, por lo que tratar de que una nación o región salga adelante sin ser parte del mismo es prácticamente imposible. En este sentido, y a pesar de que la participación de la región centroamericana en el concierto mundial no sea significativa por los flujos comerciales que se manejan, se hace necesario potenciar la agenda comercial de los distintos países y de la región y aprovechar al máximo los ACR que se tienen. Se cuenta con el enorme beneficio de ser un mercado atractivo para otros países y para regiones por todos 
los componentes que se poseen, así se tienen muchos acuerdos comerciales a la fecha. Por ende, el siguiente paso es modificar la matriz exportadora, aprovechando los increíbles recursos naturales e implementando estrategias que permitan diversificar la producción hacia sectores especializados. En ese sentido, uno de los pasos importantes a efectuar dentro de todo este proceso es la profundización de las relaciones comerciales con otras regiones y países de manera conjunta para negociar los acuerdos comerciales de una mejor manera, así como la reciente firma del acuerdo comercial de la región con Corea del Sur, o la apertura de relaciones diplomáticas con China de parte de algunos países centroamericanos, que puede dar paso a relaciones más profundas donde podríamos salir beneficiados, siempre y cuando se establezcan claramente las reglas del juego desde el inicio.

\section{Referencias bibliográficas}

- Aráuz, A. (2009). El impacto de la crisis en América Central. Revista Nueva Sociedad ( $N^{\circ}$. 220). Recuperado de http://nuso.org/media/articles/downloads/3591_1.pdf

- Caldentey, P. (2014). Desafíos estratégicos de la integración centroamericana. México D.F: Publicaciones de las Naciones Unidas. Recuperado de https:// repositorio.cepal.org/bitstream/handle/11362/37135/1420587_es.pdf

- Comisión Económica para América Latina y el Caribe (CEPAL). (2017a). Estudio Económico de América Latina y el Caribe 2017: La dinámica del ciclo económico actual y los desafíos de política para dinamizar la inversión y el crecimiento. Santiago de Chile: CEPAL. Recuperado de https:// repositorio.cepal.org/bitstream/handle/11362/42001/S1700700_ es.pdf?sequence $=159 \&$ isAllowed $=y$

- (2017b). La Inversión Extranjera Directa en América Latina y El Caribe 2017. Santiago de Chile: CEPAL. Recuperado de http://www.iberglobal.com/files/2017-2/S1700431_es.pdf

- Cordero, M. (2017). Integración Económica Centroamericana. México D. F: Publicaciones de las Naciones Unidas. Recuperado de https:// repositorio.cepal.org/bitstream/handle/11362/42001/S1700700_ es.pdf?sequence $=159 \&$ is Allowed $=y$

- Egenhoff, T. y Stein, E. (2010). Crisis Financiera Mundial: Su impacto económico y social en Centroamérica. Guatemala: Fundación Konrad Adenauer. 
Recuperado de http://www.kas.de/wf/doc/kas_20622-1522-4-30. pdf?100928005349

- Fondo Monetario Internacional (FMI). (2017a). Perspectivas Económicas Regionales del FMI. Washington D. C. USA: IMF Publications Services. Recuperado de https://www.imf.org/ /media/Files/Publications/REO/ WHD/2017/May/Spanish/wreo0517-spa.ashx

. (2017b). Perspectivas Económicas Regionales del FMI. Washington D. C.USA: IMF Publications Services. Recuperado de https://www.imf.org/ / media/Files/Publications/WEO/2017/October/Spanish/pdf/WE01017ch1-sp.ashx

- Organización Mundial del Comercio (OMC). (2011). Informe sobre el Comercio Mundial. Ginebra, Suiza: Publicaciones de la OMC. Recuperado de https://www.wto.org/spanish/res_s/booksp_s/anrep_s/wtr11-2a_s.pdf

- _ (2015). Estadísticas del Comercio Internacional. Ginebra, Suiza: Publicaciones de la OMC. Recuperado de https://www.wto.org/spanish/ res_s/statis_s/its2015_s/its2015_s.pdf

- Programa Estado de la Nación (2010). Decimosexto Informe Estado de la Nación en Desarrollo Humano Sostenible. San José, Costa Rica: Programa Estado de la Nación. Recuperado de: http://www.estadonacion.or.cr/190estado-de-la-nacion/estado-de-la-nacion/127-informe-xvi-estado-de-lanacion-2010

- Ros, J. (2011). La desaceleración de la productividad en América Latina: dos interpretaciones. Economía UNAM, Vol. 8 ( $\left.\mathrm{N}^{\circ} .23\right)$. Recuperado de http:// www.economia.unam.mx/publicaciones/nueva/econunam/23/02ros.pdf 